\title{
EXTERNAL ROLLING OF A POLYGON ON CLOSED CURVILINEAR PROFILE
}

\author{
Serhit F. Pylypaka ${ }^{a}$, Mykola B. Klendil ${ }^{b}$, Viktor I. Trokhaniak ${ }^{a, *}$, \\ Tetiana A. Kresan ${ }^{a}$, Iryna Y. Hryshchenko ${ }^{a}$, Andrit S. Pastushenko ${ }^{c}$ \\ ${ }^{a}$ National University of Life and Environmental Sciences of Ukraine, Heroiv Oborony Str. 15, 03041 Kyiv, \\ Ukraine \\ ${ }^{b}$ Separated Subdivision of National University of Life and Environmental Sciences of Ukraine of Berezhany \\ agrotechnical institute, Academichna Str. 20, 47501 Berezhany, Ternopil region, Ukraine \\ ${ }^{c}$ Mykolayiv National Agrarian University, Heorhiia Honhadze Str. 9, 54020 Mykolayiv, Ukraine \\ * corresponding author: trohaniak.v@gmail.com
}

\begin{abstract}
The design of a helical surface tillage tool made of a developable helicoid section has been calculated using the methods of analytical and differential geometry, the theory of surfaces, the systems of computer-generated graphics and mathematics. A helical tool in the form of a skeleton cylinder made of bars, where there is a helical surface made of arranged sheet metal, has been developed. Such a design prevents a helical surface from becoming clogged with soil. The suggested tool operates as a roller and the soil can easily pass through the gaps between the bars. New helical harrow tools have been designed and made for this experiment. An experimental harrow equipped with helical tools has been made and used to conduct a field research. The research was aimed at determining the optimal kinematic parameters and the pattern of field movement, which allow performing the technological process of soil tillage with the performance indices that meet the agricultural requirements.
\end{abstract}

KEYWORDS: Surface tillage, helical surface, developable helicoid, approach angle, flight development, movement pattern.

\section{INTRODUCTION}

Concave soil-tillage disks are used to turn and pulverize the soil and bury residues from the last crop [1] 6 . The profile shape of cultivated soil strips and ridge height depend on the distance between the disks, their design parameters and the setting angles. A disk is set in such a way that there is a certain approach angle between the plane of blade (disk edge) position and the direction of the unit movement. In order to improve digging, a disk is deflected in a vertical plane as well, thus, every disk has its own axle attachment to frame. If a helical surface is applied, similar performance results can be expected, but it can be attached on a shaft similar to a huller battery.

Disk tools are widely applied for surface soil-tilling. Designing and calculation of soil-tilling implementation have been thoroughly studied by P. Zaika [7]. The analytical model of soil-tillage concave disks has been developed in order to determine their geometrical and technological characteristics [8 12]. Certain papers consider various aspects of the improvement of the quality of soil tillage performed by such tools [1320. The perspectives of further investigations on the improvement of disk and other soil-tilling equipment have been determined by the scientists [21 29].

\section{MATERIALS AND METHODS}

A developable screw surface can be made by extending a flat ring along a shaft axis (Fig. 1a). The maximal pitch $I$ is formed when rectilinear generators, along which the bending takes place, become tangent to a helical line on the cylinder of radius $\partial$. This line is called the edge of regression and has a fixed angle of ascent $\varphi$. All the rectilinear generators of the surface are inclined at this angle to the plane, which is perpendicular to the surface axis. Other helical surface lines have a different angle of ascent, here, it decreases with the increase of the radius of a helical line location.

During its movement along a helical line (the edge of regression), a point rotates about its axis through the angle $t$ and, at the same time, moves along it. In one complete revolution, that is for the angle $2 \pi$, a point describes a circle $2 \pi$ ð in length on a horizontal projection and, at the same time, moves up along the surface axis at the distance of $I=2 \pi h$ - one surface pitch, where $h$ - helix parameter, $I$ - surface pitch (constant values) (Fig. 1b).

Helical surface lines on cylinder developments transform into right lines within one pitch - hypotenuses of the corresponding triangles (Fig. 1b). The values of the angle of ascent $\varphi$ for every helical line can be determined from them. Namely, in the case of the edge of regression $\operatorname{tg} \varphi=h / p$. Hence follows:

$$
\cos \varphi=\frac{p}{\sqrt{p^{2}+h^{2}}} ; \quad \sin \varphi=\frac{h}{\sqrt{p^{2}+h^{2}}} .
$$

The parametric equations of a developable helical surface, which is also called a developable helicoid, 


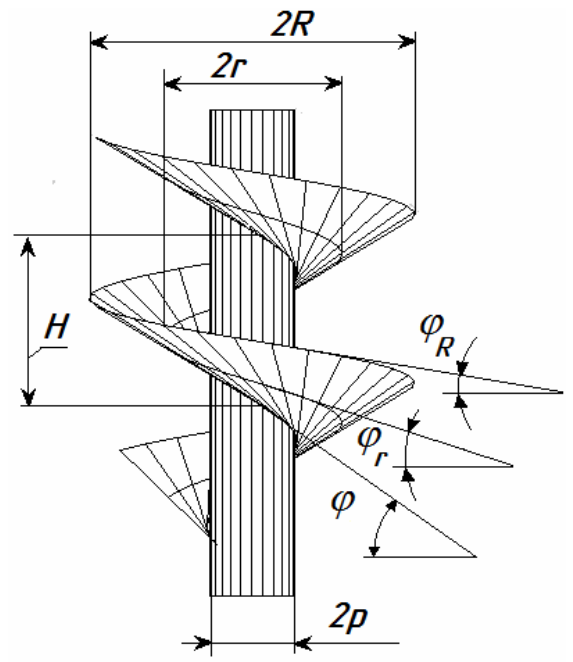

(A) . Frontal surface view.

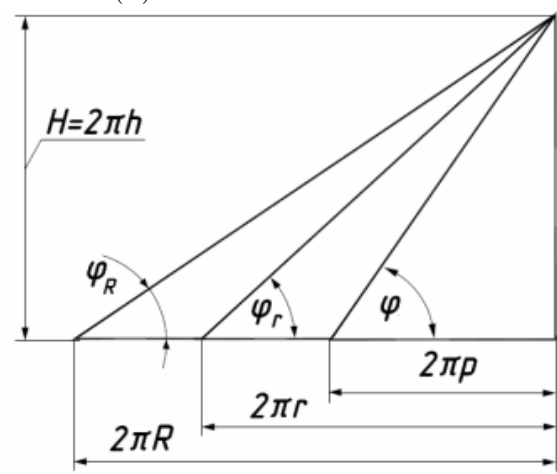

(в) . Reduced helical lines on cylinder developments of the corresponding radii.

FiguRE 1. Graphic illustrations of a helical developable surface

can be written as:

$$
\begin{aligned}
& X=p \cos t-u \frac{p}{\sqrt{p^{2}+h^{2}}} \sin t \\
& Y=p \sin t+u \frac{p}{\sqrt{p^{2}+h^{2}}} \cos t \\
& Z=h t+u \frac{h}{\sqrt{p^{2}+h^{2}}},
\end{aligned}
$$

where $t, u$ - variable surface parameters, here $t-$ the angle of point turning about the surface axis when moving to the follow point on a helical line, which is located on a cylinder radius $\Varangle ; u$ - the length of a rectilinear generator from the flow point on a helical line to the point on the surface

The angle $\varphi$ (1) is the ascent angle of the edge of regression and, at the same time, it is the inclination angle of rectilinear surface generators. In order to design a developable helicoid with the predetermined helix parameter $h$ (that is, with the pitch $I=2 \pi h$ ) and the inclination angle $\varphi$ of its rectilinear generators, according to (1), it is necessary to determine the corresponding value of the radius $\partial$ of a base cylinder where a helical line is located - the edge of regression. The angle of ascent of all the other helical surface lines is less than $\varphi$ (Fig. 1a 1b).
A helical surface is traditionally described by the equations (2) with the vertical arrangement of its axis, as it is shown in Fig. 1a If this shaft surface is placed on the soil and is extended in such a way that the axis of rotation is perpendicular to the moving direction, the angle $\varphi_{R}$ is the approach angle, however, its value is not sufficient enough to deepen the surface into the soil. It is obvious that the surface should be turned in such a way that its axis makes a certain angle with the direction of unit movement. If we take $Y$ axis for the direction of unit movement, the parametric equations of the surface (2) are of the following form:

$$
\begin{aligned}
X= & \left(p \sin t+u \frac{p \cos t}{\sqrt{p^{2}+h^{2}}}\right) \sin \beta+ \\
& +\left(h t+u \frac{h}{\sqrt{p^{2}+h^{2}}}\right) \cos \beta \\
Y= & \left(p \sin t+u \frac{p \cos t}{\sqrt{p^{2}+h^{2}}}\right) \cos \beta- \\
& -\left(h t+u \frac{h}{\sqrt{p^{2}+h^{2}}}\right) \sin \beta ; \\
Z= & p \cos t-u \frac{p \sin t}{\sqrt{p^{2}+h^{2}}} .
\end{aligned}
$$

According to the equations (3), two projections of the shaft surface were built, Fig. 2a 2b. In this case, the angle $\beta$ is the angle between the surface axis and the direction, which is perpendicular to the direction $V$ of unit movement. If $\beta=0$, the unit rolls with insufficient deepening of the helical surface into the soil. If $\beta=90^{\hat{1}}$, the deepening takes place, however, there is no rolling. It is necessary to substantiate the permissible value of the angle $\beta$ and the design parameters of the surface in order to provide its normal performance. It is possible to deepen such a construction into the soil as far as the shaft, meaning that the shaft is at working surface that interacts with the soil as well. The research shows that there is soil accumulated between the shaft and the surface and such a construction does not work. In order to avoid this phenomenon, the depth of the helical surface deepening into the soil can be decreased by limiting it with a cylindrical shaft of a larger diameter. Furthermore, the cylinder should be made of bars in such a way that it acts as a roller and the soil can easily pass through the gaps between the bars.

Fig. 3a 3b presents the projections of the surface, which depth of deepening into the soil is limited by means of the increased diameter of a cylindrical shaft. In the frontal projection, it is conditionally shown to be solid, however, it should be made of rolled metal with the density sufficient enough for the soil to pass through the gaps. In the horizontal projection, the shaft is not presented at all in order to show certain geometrical characteristics. First of all, they include an approach angle. In the case of a soil-tillage concave disk, this is the angle between the blade plane and the 


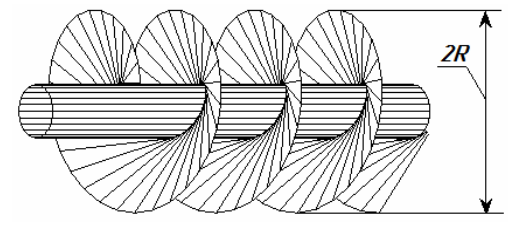

(A).

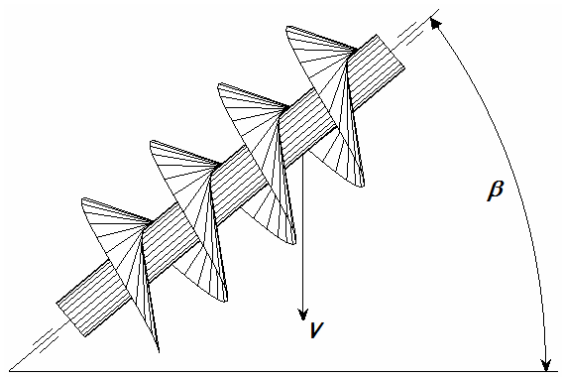

(в).

Figure 2. Projections of a shaft helical surface with the axis turned in the direction of unit movement

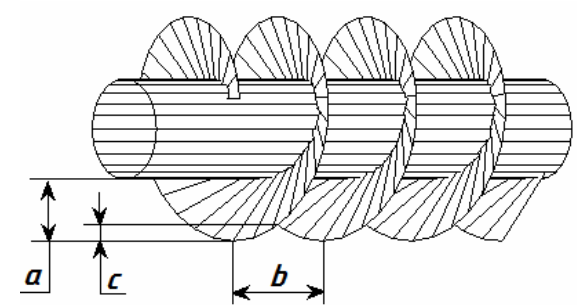

(A).

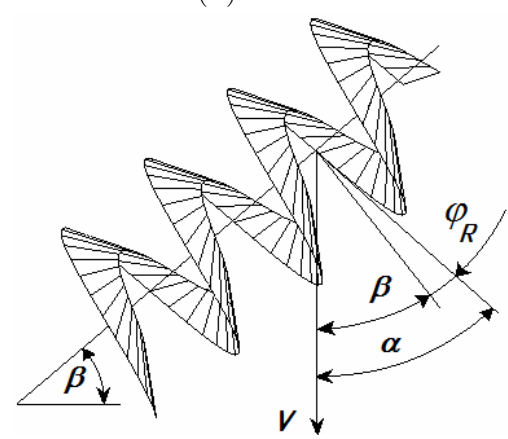

(B).

Figure 3. Projections of the soil-tilling helical surface with the depth of its deepening into the soil being decreased by means of increasing the diameter of a limiting cylinder

direction of unit movement (if a disk is arranged in a vertical plane without a roll angle) 44. The cutting edge of a helical surface is a helical line (a space curve).

A similarity between both surfaces can be found. This is the angle that is formed by a tangent to the cutting edge in its lowest part with the unit moving direction. This determination is appropriate for a concave disk, which has a roll angle, as well.

In the horizontal projection (Fig. 3a 3b), the surface axis is presented in such a way that there are blind spots, which is necessary in order to understand where the upper flight is and where the lower one is. At one of the points of the lower flight, which can be imagined as being the contact point of the cutting edge and the soil, the approach angle $\alpha$ is shown. According to the Figure, it can be written that:

$$
\alpha=\beta+\varphi_{R},
$$

where $\varphi_{R}$ - the angle of ascent of a helical line (Fig. 1a), that is, the ascent angle of the cutting edge. According to the right-angled triangles (Fig. 1b), it can be determined that:

$$
\operatorname{tg} \varphi_{R}=\frac{h}{R} ; \quad \operatorname{tg} \varphi=\frac{h}{p} .
$$

If $\beta=0$ (that is, the rotation axis of the helical surface construction is perpendicular to the unit moving direction), the approach angle is $\varphi_{R}$, according to (4). In the case of a soil-tillage disk, the approach angle is equal to zero under these conditions. In general, the range of approach angle values is rather wide for concave disks. According to the obtained relations (4), (5), it can be determined which parameters influence its value. However, it is worth taking into account the other parameters presented in the frontal projection (Fig. 3a 3b): the depth of tillage $\grave{a}$, the height of ridges $\tilde{n}$, the distance between the ridges $b$. The parameters $b$ and $c$ depend on the form of a helical surface edge, that is, on a helical line, which is limited by the radius $R$ and the angle $\beta$. The depth of soil tillage $\grave{a}$ is the difference between the radius $R$ and the radius $r: a=R-r$.

Let us consider a separate helical line - the cutting edge of a helicoid surface with its axis being inclined at the angle $\beta$ to a direction that is perpendicular to the unit movement (Fig. $4 \mathrm{a} 4 \mathrm{~b}$ ).

According to the right-angled triangle in the horizontal projection, it can be written as:

$$
b=H \cos \beta=2 \pi h \cos \beta .
$$

Thus, it is possible to determine the helix parameter of the helicoid:

$$
h=\frac{b}{2 \pi \cos \beta}
$$

The radius $R$ of the cutting edge is predetermined and the helix parameter $h$ is determined according to the formula (7). These two values allow for constructing a helical line. Here, it is possible to change the angle $\beta$ and the invariable distance $b$ within certain limits.

It is obvious that the ridge height $\tilde{n}$ can vary within small limits.

\section{Result}

Fig. $4 \mathrm{a} 4 \mathrm{~b}$ shows a helical line built to a scale under $R=0.25 \mathrm{~m}, b=0.2 \mathrm{~m}, \beta=40^{\circ}$. The area in the frontal projection, which is highlighted in grey, is illustrative of a tilled soil layer. 


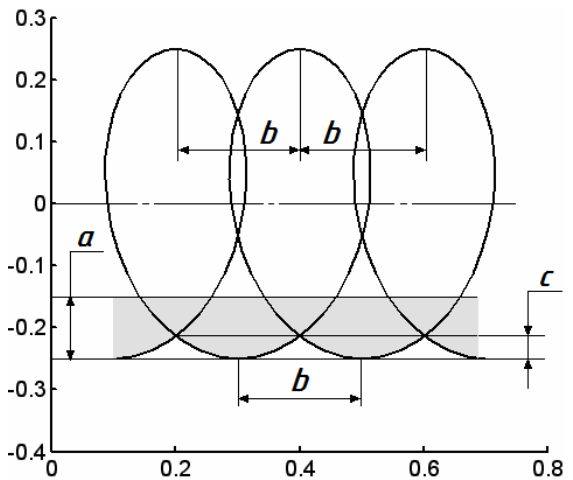

(A).

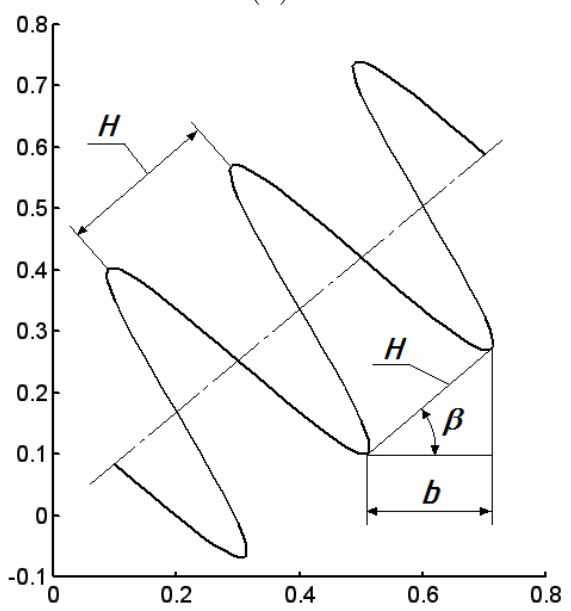

(в).

Figure 4. Projections of a helical line - the helicoid cutting edge

Let us determine the radius $\partial$ of the base cylinder where the edge of regression is located. According to (5) and (7), let us write:

$$
p=h \operatorname{ctg} \varphi=\frac{b \operatorname{ctg} \varphi}{2 \pi \cos \beta} .
$$

When determining the radius $\partial$, there is a certain freedom in choosing the ascent angle $\varphi$ of the edge of regression. Its value has certain limits, which will be discussed below. This angle is equal to the angle of inclination of the surface generators to a horizontal plane (Fig. 1a). It is obvious that it can influence the operating process flow. In this case, let us assume that $\varphi=30^{\circ}$. Then, according to 8 , taking into account the above set design parameters, the following can be determined: $\partial=0.0721 \mathrm{~m}$. According to the expression (7), a helix parameter is determined: $h=$ 0.0416 . The radius of the base cylinder $\partial$ and the helix parameter $h$ allow for building the surface of a developable helicoid, according to the equations (2). The number of flights depends on the range of values of the variable $t$ (one flight corresponds to the value $t=0 \ldots 2 \pi$ ), and the radius $R$ of the cylinder, where the surface cutting edge is located, depends on the range of values of the variable $u$. In order to determine the length $u$ of a rectilinear surface generator beginning from the edge of regression $(u=$

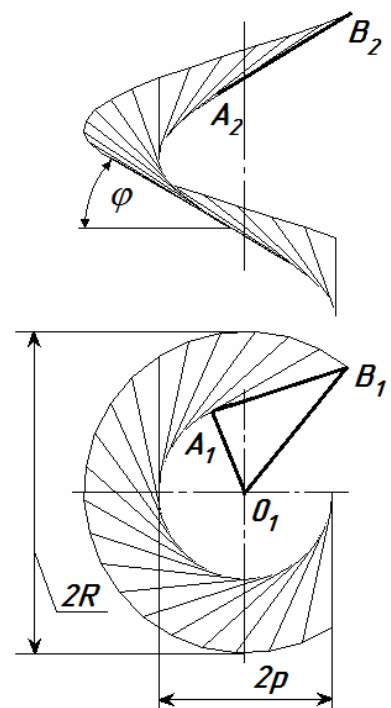

FiguRE 5. Determination of the required length $u$ of a rectilinear surface generator

0 ) to the final value of $u$, which corresponds to the assumed radius $R$, let us apply the projections of the surface (Fig. 5). The rectilinear generator $\grave{A} \hat{A}$ is inclined to the horizontal plane at an angle of $\varphi$. Its horizontal projection can be determined from the right-angled triangle $\hat{I}_{1} \grave{A}_{1} \hat{A}_{1}$. Taking into account that $\hat{I}_{1} \hat{A}_{1}=\partial, \hat{I}_{1} \hat{A}_{1}=R$, we determine:

$$
u=\sqrt{R^{2}-p^{2}} .
$$

The real length $u$ of the rectilinear generator $\grave{A} \hat{A}$ is determined taking into account its angle of inclination $\varphi$ to the horizontal plane (Fig. 5):

$$
u=\frac{\sqrt{R^{2}-p^{2}}}{\cos \varphi} .
$$

The expression for determining the length $u$ of a rectilinear generator can be written through the radius $R$, the angle $\varphi$ and the helix parameter $h$. Taking into account that, according to (8), $p=h \operatorname{ctg} \varphi$, the expression 10 takes the following form:

$$
u=\frac{\sqrt{R^{2} \sin ^{2} \varphi-h^{2} \cos ^{2} \varphi}}{\sin \varphi \cos \varphi} .
$$

For the specified values $R=0.25 \mathrm{~m}, h=0.0416$ and $\varphi=30^{\hat{1}}$, it has been determined that $u=0.2745 \mathrm{~m}$. Fig. 6a presents the frontal projection of one surface flight, which was built according to the equations (2) with the parameter $u$ within the limits of $u=$ 0 . . .0.2745 m.

The surface should be limited by the internal cylinder of the radius $r$ in order to provide the required tillage depth. The tillage depth is assumed to be à $=0.1 \mathrm{~m}$. Then $r=R-a=0.15 \mathrm{~m}$. According to the formula (11), let us find the values of $u$ for a cylinder of the radius $r$, that is, $r$ is inserted instead of $R$ and we obtain $u=0.1519$. 


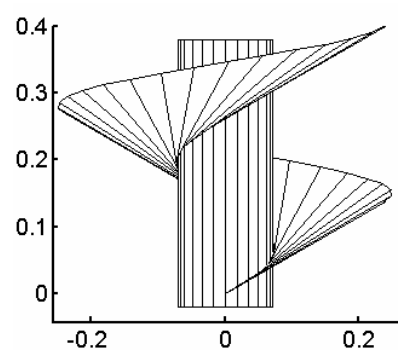

(A).

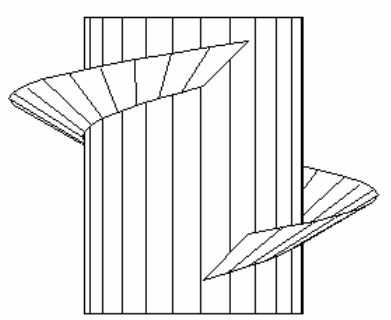

(в).

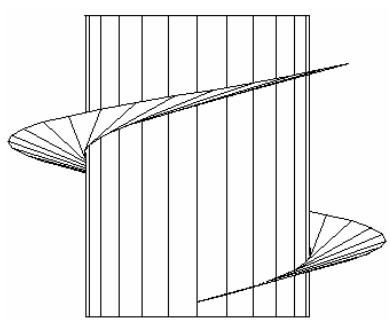

(C).

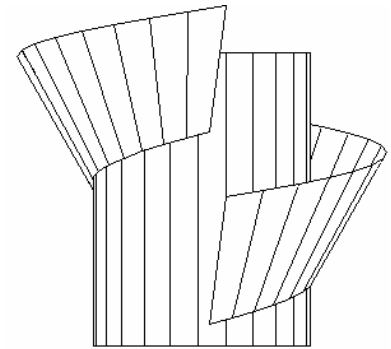

(D).

FiguRE 6. Frontal projection of one flight of a developable helicoid, which is built according to the equations 2 with the given data: $R=0.25 \mathrm{~m}, h=0.0416$ : a) $p=r=0.072 \mathrm{~m}, \varphi=30^{\hat{1}}$; b) $p=0.072 \mathrm{~m}, r=0.15 \mathrm{~m}, \varphi=30^{\hat{1}}$; c) $p=r=0.15 \mathrm{~m}, \varphi=15.5^{\hat{1}}$; d) $p=0.024 \mathrm{~m}, r=0.15 \mathrm{~m}, \varphi=60^{\hat{1}}$.

The necessary surface section is built according to the equations (2) on the change of the parameter $u$ within the limits of $u=0.1519 \ldots 0.2745 \mathrm{~m}$. Fig. $6 \mathrm{~b}$ presents the constructed surface flight.

According to (8), the radius $\partial$ of the base cylinder depends on the helix parameter $h$ and the inclination angle of helicoid generators. As it has been mentioned above, there is a certain freedom in choosing the angle $\varphi$. If it is changed, the radius $\partial$ is changed as well. However, it can be larger than the one of the internal limiting cylinder of the radius $r$, that is, $\partial \leq r$. It can be explained by the fact that there is no surface inside the cylinder of the radius $\partial$. Thus, the maximum possible value of the radius $\partial$ is equal to $\partial=R-a$, that is, $\partial=r$. If $\partial=r=0.15 \mathrm{~m}$, we can determine the following from (8): $\varphi=15.5^{\hat{1}}$. This value of the angle $\varphi$ is the minimum one for the set radius $R$ and the tillage depth $\grave{a}$. The limits of variation of the parameter $u$ are determined according to the formula (11): $u=0 \ldots 0.2075 \mathrm{~m}$. Fig. $6 \mathrm{c}$ presents the frontal projection of one surface flight with $ð=$ 0.15 and $h=0.0416$. One more surface flight was built with $\varphi=60^{\hat{1}}$ for illustrative purposes (Fig. 6d). The parameters for this angle are the following: $\delta=$ $0.024 \mathrm{~m}, u=0.2987 \ldots 0.4992 \mathrm{~m}$. Having analyzed the surface flights with various angles of inclination of the generators (Fig. 6b, 6c, 6d), is can be assumed that their deepening force is different and the quality of soil turning and its mixing with crop residues is different as well. Similar to the disk performance, this helical tool angle can act as a roll angle for disk implements.

Fig. 7a $7 \mathrm{~b}$ presents a scale frontal and horizontal projections of a helical tool for surface tillage at the depth of à $=0.10 \mathrm{~m}$ with the set distance between the ridges being $b=0.2 \mathrm{~m}$.

The design parameters of the presented tool are the following: the radii $R=0.25 \mathrm{~m}, r=0.15 \mathrm{~m}$, the helix parameter $h=0.0416$. The helicoid axis is inclined at an angle $\beta=40^{\hat{1}}$ to the direction, which is perpendicular to the unit moving direction. The approach angle is determined according to the expression (4). According to (5), the ascent angle $\varphi_{R}$ of the cutting edge is equal to $\varphi_{R}=\operatorname{arctg}(h / R)=9.4^{\hat{1}}$. Thus, the approach angle is $\alpha=49.4^{\hat{1}}$. The assumed angle of

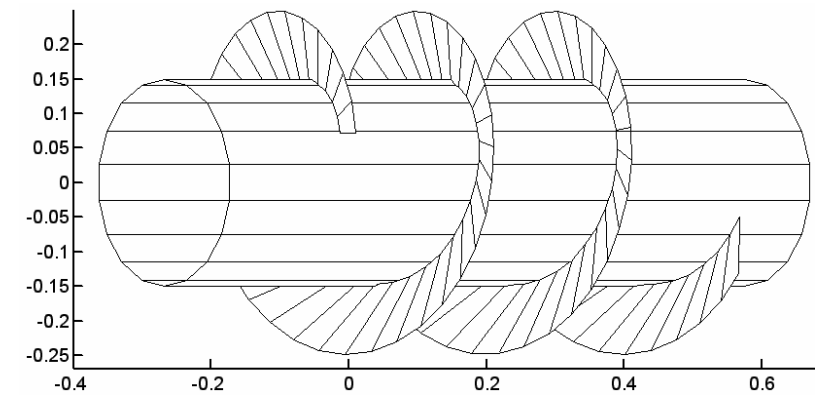

(A).

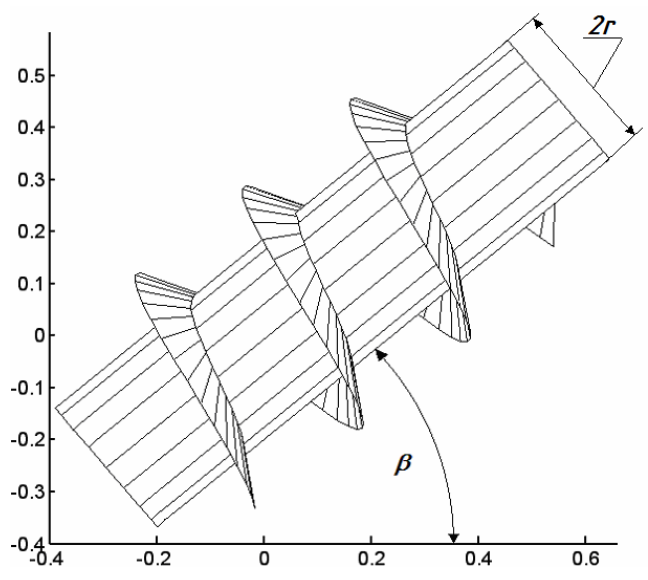

(B).

Figure 7. Projections of a tillage tool made of a developable helicoid surface designed according to the predetermined tillage depth à $=0.1 \mathrm{~m}$ and the distance between the ridges $b=0.2 \mathrm{~m}$.

inclination of the rectilinear generators is equal to $\varphi=30^{\hat{1}}$.

According to the theoretically determined design parameters of helicoid flights (Table 1), helical harrow tools (Fig. 8) as well as an experimental harrow equipped with helical tools were designed and made (Fig. 9).

In order to determine the performance indices of a harrow equipped with helical tools, A field test of the experimental harrow was conducted. The investigation was aimed at determining the influence of parameters such as the unit speed, the predetermined 


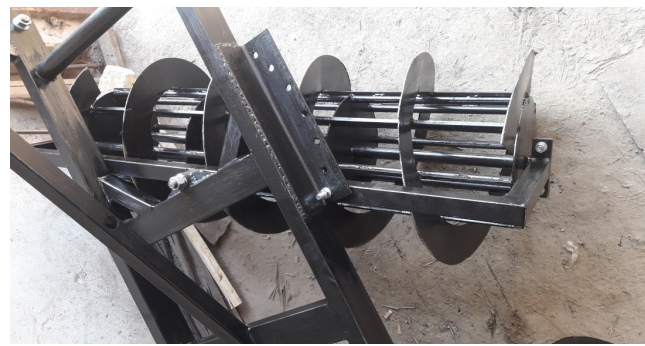

Figure 8. Overall view of the helical tool.

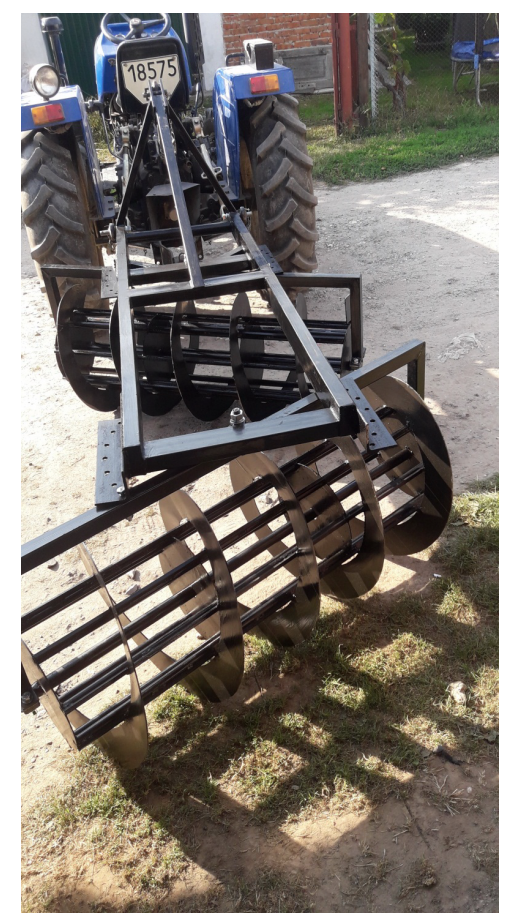

FIGURE 9. Overall view of the harrow equipped with helical tools.

tillage depth and the movement pattern on the quality indices of helical harrow performance.

The research programme included the evaluation of a helical harrow performance under various moving directions relative to the location of a row: movement along a row, at the angle of $20^{\circ}$ and at the angle of $40^{\circ}$. The indices that characterize field conditions are presented in Table 2

The quality indices were determined according to the standardized procedures: Agricultural Technology. Methods for Determining Investigation Conditions: KND 46.16.02.08-95. State Committee of Ukraine for Standardization and Metrology;

(1.) RD.10.4.2-89. Testing Agricultural Machinery. Surface Tillage Machinery and Tools. Testing Programme and Procedure. State Committee of Ukraine for Standardization and Metrology;

(2.) KND.46.16.02.-96. Agricultural Machinery. Set of Quality Indices;

(3.) Procedure of Investigating Process Quality Indices, self-developed.
The tillage depth of the tools was measured using a purpose-made graduated metal feeler. The feeler was deepened into the soil until it came in contact with the foot formed by a helical surface. Then, the feeler graduation mark was evaluated and recorded. The obtained data were used to analyse the consistency of tillage depth by helical tools and the deviation of the average actual tillage depth from the predetermined one.

The depth and the height of ridges after tilling the soil by a harrow equipped with helical tools were determined with the use of a two-meter rod, which was placed on the ridges, and a ruler, which was arranged at the furrow bottom. The obtained data were recorded in the experiment documentation.

For each factor (unit speed, unit movement patters, tillage depth and the height of ridges) the experiment was conducted no fewer than 5 times in order to avoid any error in the mean result, which was then used for statistical experimental data processing. The standard deviation of the results was equal to up to $5 \%$.

Fig. 10 presents the comparison of the indicators of deviation from the predetermined tillage depth for three movement patterns with the set depth of $10 \mathrm{~cm}$.

According to the characteristic curve (Fig. 10), if the unit moves along a row, the largest deviations $(12.1 \%)$ were recorded for the unit speed of $8 \mathrm{~km} / \mathrm{h}$ and the smallest deviation values were observed for the unit speed of $10 \mathrm{~km} / \mathrm{h}(3.8 \%)$.

If the unit moves at an angle of $20^{\circ}$ to a row, the smallest deviations $(1.2 \%)$ were recorded for the unit speed within the range of $12-14 \mathrm{~km} / \mathrm{h}$.

If the unit moves at an angle of $40^{\circ}$ to a row, the smallest deviations $(0.5 \%)$ were recorded for the unit speed of $12 \mathrm{~km} / \mathrm{h}$.

It is worth mentioning that in all the cases of unit moving direction, the values of depth deviations did not exceed the ones stated in the agricultural requirements.

If the predetermined tillage depth was equal to 10 $\mathrm{cm}$ (Fig. 10), the unit produced better results being under the angle of $20^{\circ}$ to a row, except for the speed range of $8-10 \mathrm{~km} / \mathrm{h}$. Here, it is worth mentioning that within the unit speed range from 12 to $14 \mathrm{~km} / \mathrm{h}$, the deviation values did not substantially vary and were equal to about $5 \%$.

According to the agricultural requirements, a furrow bottom profile after disking should not exceed $5 \mathrm{~cm}$.

Fig. 11 presents the comparison of furrow bottom profile indicators for three various movement patterns at the predetermined tillage depth of $10 \mathrm{~cm}$.

After harrowing at the depth of $10 \mathrm{~cm}$ (Fig. $4 \mathrm{a} 4 \mathrm{~b}$ within the speed range of $8-12 \mathrm{~km} / \mathrm{h}$, better results were obtained in the case of movement at an angle of $40^{\circ}$ to a row, while in the case of straightforward movement, the furrow bottom profile values exceeded the permissible ones, according to the agricultural requirements. However, within the speed range of 12 


\begin{tabular}{ll}
\hline Parameter & Value \\
\hline Design operating width, $\mathrm{m}$ & 1.3 \\
Tractor power requirements, h.p. & from 40 \\
Mounting on a tractor & attached \\
Weight, kg & 172 \\
Number of helicoid flights, pcs & 10 \\
Outer helicoid diameter, mm & 566 \\
Tillage depth, cm & $3-12$ \\
Operating speed, km $/ \mathrm{h}$ & $7 \ldots 17$ \\
Transport dimensions $(\mathrm{L} \times \mathrm{B} \times \mathrm{H})$ & $2090 \times 1430 \times 1250$ \\
\hline
\end{tabular}

TABLE 1. Specification of a harrow equipped with helical tools.

\begin{tabular}{|c|c|c|}
\hline Condition indicators & & $\begin{array}{l}\text { Background (after corn } \\
\text { kernels are harvested) }\end{array}$ \\
\hline Air humidity, $\%$ & & 82 \\
\hline Wind speed, $\mathrm{m} / \mathrm{s}$ & & 0.6 \\
\hline \multirow[t]{3}{*}{ Soil moisture $(\%)$ in the following layers: } & $0-5 \mathrm{~cm}$ & 17.75 \\
\hline & $5-10 \mathrm{~cm}$ & 17.14 \\
\hline & $10-15 \mathrm{~cm}$ & 17.47 \\
\hline Field weediness before the unit passes through: $\mathrm{pcs} / \mathrm{m}^{2}$ & & 6.0 \\
\hline Stubble height, cm & & 31.0 \\
\hline Material moisture content, $\%$ & & 61.16 \\
\hline Mass of plant residues, $\mathrm{g} / \mathrm{m}^{2}$ & & 2864 \\
\hline
\end{tabular}

TABLE 2. Test operating conditions of a harrow equipped with helical tools.

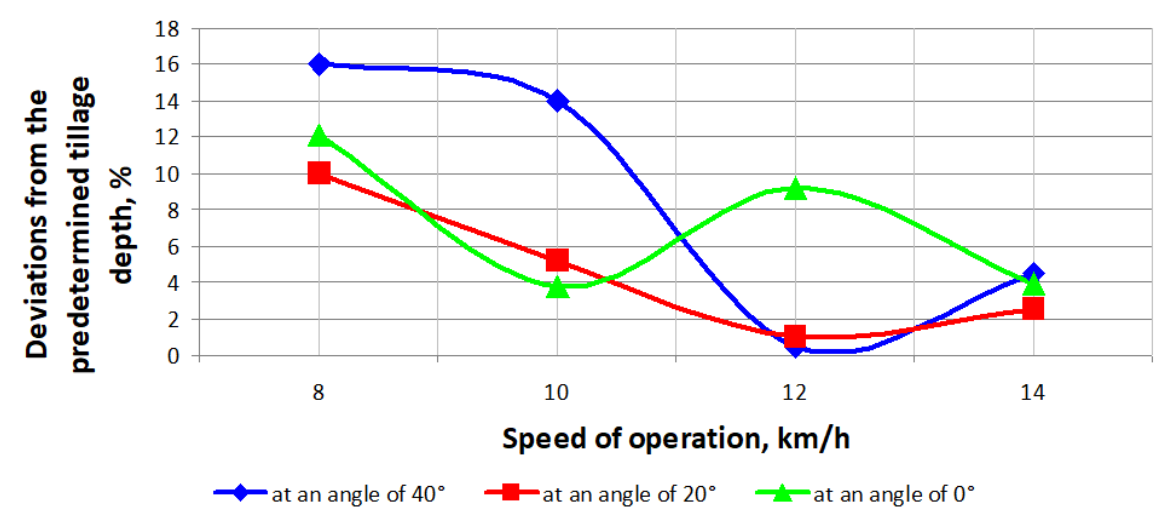

Figure 10. Tillage depth deviations under various movement patterns.

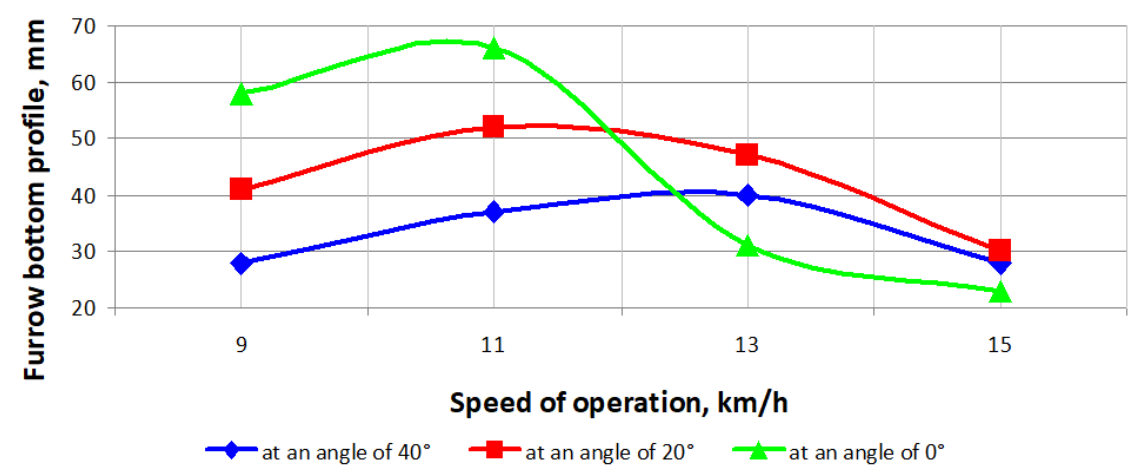

FiguRE 11. Furrow bottom profile under various movement patterns. 
$-16 \mathrm{~km} / \mathrm{h}$, better results were produced in the case of movement along a row, here, the agricultural requirements were met for all three movement patterns.

\section{Conclusions}

In order to till the soil to a shallow depth, disk tools are widely used. Every disk has its own axel mounting providing the predetermined approach and roll angles for an effective unit performance. If a helical operating surface in the form of developable helicoid flights is used, it is possible to provide surface tillage with the predetermined depth and the distance between the ridges of the tilled soil. Here, the unit design is simplified, since only two assemblies with bearings at their ends are necessary to provide the rotation of a cylinder with a helical operating surface attached to it. The analysis of the field experiment data allowed for determining the optimal parameters of the tillage combine speed, the tillage depth and the field movement pattern, which provide the performance of the disk soil tillage with the operation indices that meet the agricultural requirements. Thus, in the case of all three directions of unit movement, the values of the deviation from the predetermined tillage depth did not exceed the required $2.0 \mathrm{~cm}$, according to the agricultural requirements. According to the furrow bottom profile indicator, the pattern of movement at an angle of $40^{\circ}$ to a row is considered to be better, since the agricultural requirements were met under all three movement speeds.

\section{REFERENCES}

[1] V. M. Salokhe, N. B. A. Quang. Dynamics of a powered disk in clay soil. Journal of Terramechanics 32(5):231 244, 1995. DOI:10.1016/0022-4898(95)00019-4

[2] E. M. Tice, J. G. Hendrick. Disc coulter operating characteristics. Transactions of the ASABE 35(1):3 16, 1992. DOI:10.13031/2013.28562

[3] Z. Zeng, Y. Chen. Performance evaluation of fluted coulters and rippled discs for vertical tillage. Soil and Tillage Research 183:93 - 99, 2018. DOI:10.1016/j.still.2018.06.003.

[4] V. F. Strelbytskyi. Disk Tillage Machinery. Machine Engineering, Moscow, 1978.

[5] M. Z. Tsymmerman. Tillage Machinery Tools. Machine Engineering, Moscow, 1978.

[6] P. S. Nartov. Disk Tillage tools. VGU Press, Voronezh, 1972.

[7] P. M. Zaika. Theory of Agricultural Machinery. Soiltilling Machinery and Equipment. Oko, Kharkiv, 2001.

[8] S. Pylypaka, M. Klendii, V. Trokhaniak. Particle motion over a plane, which rotates about a horizontal axis and makes a certain angle with it. Bulletin of the Karaganda University Mathematics series 93:1 - 129, 2019 .

[9] S. F. Pylypaka, M. B. Klendii, O. M. Klendii. Particle motion over the surface of a rotary vertical axis helicoid. INMATEN-Agricultural enginering 51(1):15 - 28, 2017.
[10] S. Pylypaka, M. Klendii, O. Klendii. Particle motion on the surface of a concave soil-tilling disk. Acta Polytechnica 58(3):201 - 208, 2018.

[11] S. F. Pylypaka, M. B. Klendii, V. M. Nesvidomin, V. I. Trokhaniak. Particle motion over the edge of an inclined plane that performs axial movement in a vertical limiting cylinder. Acta Polytechnica 59(1):67 - 76, 2019.

[12] S. Pylypaka, V. Nesvidomin, M. Klendii, et al. Conveyance of a particle by a vertical screw, which is limited by a coaxial fixed cylinder. Bulletin of the Karaganda University Mathematics series 95(3):108 $118,2019$.

[13] G. R. Maharjan, A.-K. Prescher, C. Nendel, et al. Approaches to model the impact of tillage implements on soil physical and nutrient properties in different agro-ecosystem models. Soil and Tillage Research 180:210 - 221, 2018. DOI:10.1016/j.still.2018.03.009

[14] V. Milkevych, L. J. Munkholm, Y. Chen, T. Nyord. Modelling approach for soil displacement in tillage using discrete element method. Soil and Tillage Research 183:60 - 71, 2018.

[15] P. Owen, P. Cleary. Screw conveyor performance: Comparison of discrete element modelling with laboratory experiments. Progress in Computational Fluid Dynamics An International Journal 10:327 - 333, 2010. DOI:10.1504/PCFD.2010.035366.

[16] S. Pylypaka, M. Klendii, T. Kremets, O. M. Klendii. Particle motion over the surface of a cylinder, which performs translational oscillations in a vertical plane. Engineering Journal 22(3):83 - 92, 2018.

[17] O. Hrynenko, S. Lebedev. Investigations on disk tillage tool oscillations. Design and Enguneering Aspects of Development and Testing New Agricultural Technologies in Ukraine 15:50 - 53, 2011.

[18] A. Kyrychenko, K. Sokht. Evaluation of soil-tilling quality performed by concave disks with independent suspension. In Mechanization in Grain Production and Selection Process, p. 18. Krasnodar, 1985.

[19] O. Haponenko. Programming the uniformity of soil tilling by disk tools on spring shanks. Collection of Scientific Papers of Vinnytsia National Agrarian University Series: Technical Sciences 11:135 - 141, 201.

[20] V. Kravchuk, M. Hrytsyshyn, S. Koval. Modern Tendencies in the Development of Agricultural Machinery Designs. Agrarian Sciences, Kyiv, 2004.

[21] M. Abo-Elnor, R. Hamilton, J. T. Boyle. Simulation of soil-blade interaction for sandy soil using advanced 3d finite element analysis. Soil and Tillage Research 75(1):61 - 73, 2004. DOI:10.1016/S0167-1987(03)00156-9

[22] M. Amantayev, G. Gaifullin, R. Kravchenko, et al. Investigation of the furrow formation by the disc tillage tools. Bulgarian Journal of Agricultural Science 24(4):704 - 709, 2018.

[23] R. B. Hevko, M. V. Liubin, O. A. Tokarchuk, et al. Determination of the parameters of transporting and mixing feed mixtures along the curvilinear paths of tubular conveyors. INMATEN-Agricultural enginering 55(2):97 - 104, 2018. 
[24] R. B. Hevko, O. M. Strishenets, O. L. Lyashuk, et al. Development of a pneumatic screw conveyor design and substantiation of its parameters. INMATEN-

Agricultural enginering 54(1):153 - 160, 2018.

[25] R. Hevko, I. Tkachenko, S. Synii, I. Flonts. Development of design and investigation of operation processes of small-sclale root crop and potato harvesters. INMATEN-Agricultural enginering 49(2):53 - 60, 2016.

[26] H.-K. Hong, C.-S. Liu. Non-sticking oscillation formulae for coulomb friction under harmonic loading. Journal of Sound and Vibration 244(5):883 - 898, 2001. DOI:10.1006/jsvi.2001.3519

[27] M. B. Klendii, O. M. Klendii. Interrelation between incidence angle and roll angle of concave disks of soil tillage implements. INMATEH-Agricultural Engineering 49(2):13 - 20, 2016.
[28] S. N. Krivoshapko, M. Rynkovskaya. Five types of ruled helical surfaces for helical conveyers, support anchors and screws. In 3rd International Conference on Mechatronics and Mechanical Engineering (ICMME), vol. 95 of MATEC Web of Conferences. 2017. DOI:10.1051/matecconf/20179506002.

[29] P. S. G. Magalhães, A. Bianchini, O. A. Braunbeck. Simulated and experimental analyses of a toothed rolling coulter for cutting crop residues. Biosystems Engineering 96(2):193 - 200, 2007.

DOI:10.1016/j.biosystemseng.2006.10.014 